\title{
Educação ambiental: origens, reformulações e avanços no ensino e na pesquisa da pós-graduação - o caso do Doutorado MADE-UFPR
}

\section{Environmental education: origins, reformulations and advances in graduate-level teaching and research - the Ph.D case MADE-UFPR}

\author{
Maria do Rosário KNECHTEL*
}

\section{RESUMO}

Este artigo tem por objetivo trazer uma abordagem sobre aspectos das origens e avanços da Educação Ambiental no contexto do Curso de Doutorado em Meio Ambiente e Desenvolvimento da UFPR. Buscamos expor as primeiras idéias que geraram outras e permitiram construir o Programa Interdisciplinar do Doutorado, o projeto, o plano de ensino com as primeiras ementas, os conteúdos socioambientais e da educação trabalhados no ensino e na pesquisa do referido curso. A epistemologia da EA privilegiou a construção de conhecimentos, no momento em que o mundo, o meio ambiente e a educação oscilam entre a modernidade e a pós-modernidade. Infere-se que a EA apresenta uma produção de conhecimento emergente e que a ciência, frente às novas tendências, trata das complexidades do mundo e das complexidades ambientais interdisciplinarmente.

Palavras-chave: educação ambiental, curso de doutorado, epistemologia, ensino e pesquisa na pósgraduação.

\begin{abstract}
This article aims at approaching some aspects of the origins and advances made in environmental education within the context of a doctoral program about the environment and development, at UFPR (Federal University of Paraná). We tried to present the initial ideas that, having led to others, allowed us to set up the doctoral program's interdisciplinary content, the project, the teaching plan with its first adjustments, the socio-environmental and educational contents developed for teaching and carrying out research. The epistemology of environmental education privileged the construction of knowledge at a time when the world, the environment, and education are swinging between modernity and post-modernity. It is inferred
\end{abstract}

\footnotetext{
* Doutora em Sociologia da Educação. Professora do Doutorado em Meio Ambiente e Desenvolvimento da UFPR. Coordenadora do Curso de Especialização em
} Educação Ambiental da UFPR. knechtel@fesppr.br 
KNECHTEL, M. do R. Educação ambiental: origens, reformulações e avanços...

that environmental education presents an emerging production of knowledge and that science, facing the new trends, addresses the complexities of the world and the environmental complexities in an interdisciplinary way.

Key-words: environmental education, doctoral program, epistemology, graduate-level teaching and research.

As sociedades defrontam-se permanentemente com a necessidade de novas definições e de novas diretrizes para o desenvolvimento de percepções do mundo, relacionadas à busca de uma economia e de uma vida social mais justa, o que é próprio do processo histórico.

A evidência da necessidade de inclusão da dimensão ambiental na educação, aponta para a emergência do pensar a crise socioambiental, para o reconhecimento mundial da complexidade dos problemas que afetam o meio ambiente e para a busca de novos estilos de desenvolvimento sustentável.

Desde a proposição no princípio 19 da Declaração de Estocolmo (1972), mostra-se para o mundo a necessidade de uma Educação Ambiental, ampla, mesmo que com algumas limitações quando de seu início.

Nesta perspectiva, o texto em pauta traz à tona preocupações e reflexões sobre as questões ambientais que geraram no contexto da UFPR, a proposta de criação do Curso de Doutorado em Meio Ambiente e Desenvolvimento, agora, comemorando seus 10 anos. Abordamos aspectos das origens do curso, reformulações e avanços no ensino e na pesquisa, incluída a Educação Ambiental.

No anfiteatro das Ciências Jurídicas, em 1994, após reuniões e discussões iniciais, um grupo de professores pesquisadores da UFPR, com a participação de pesquisadores da França (em convênio com a Universidade Paris VII e Universidade de Bordeaux), se propunham construir o Programa Interdisciplinar do Doutorado em Meio Ambiente e Desenvolvimento. Neste contexto foi o nascedouro do referido curso e também da disciplina Educação Ambiental.

Apresentaram-se os docentes de meio ambiente e, em seguida questões ambientais foram colocadas; surgiram as primeiras idéias que geraram outras e permitiram esboçar um projeto e posteriormente um plano de ensino com as primeiras ementas e, entre estas a ementa para a Educação Ambiental, norteadora do conteúdo programático, das abordagens socioambientais e pedagógicas no ensino e na pesquisa, a serem trabalhadas com os doutorandos da $1^{\mathrm{a}}$ Turma.
O ementário das disciplinas foi sendo construído pelos professores procedentes das diferentes áreas do conhecimento, já preocupados com o sentido de busca de sua integração, isto é, de construção do processo interdisciplinar, quer no ensino, quer na pesquisa, o que não foi fácil. Defrontam-se desafios a cada ano que passa e a cada novo grupo de doutorandos que ingressa, todavia com avanços também.

As bases constitutivas e de acesso ao conhecimento nas disciplinas e nas oficinas do curso, e em Educação Ambiental expressas nas ementas, nos conhecimentos e metodologias construídas interdisciplinarmente tiveram como núcleo temático de ensino e pesquisa, na $1^{\mathrm{a}}$ Turma: o Meio Ambiente e Desenvolvimento da Região Costeira do Paraná (em 14 teses 1996). A produção de conhecimento da $2^{\text {a }}$ Turma foi centrada no Meio Ambiente e Desenvolvimento de Curitiba e Região Metropolitana (1999) e na $3^{\mathrm{a}} \mathrm{e}$ $4^{\text {a }}$ Turma (2001-2003) os temas diversificaram quanto ao espaço social e geográfico e problemas de pesquisa, sem deixar de lado naturalmente as atividades interdisciplinares nos seminários e nas oficinas de pesquisa.

A vinculação da referida disciplina ao ensino e à pesquisa no Curso de Doutorado ensejou a construção epistemológica da Educação Ambiental apoiada, logo de início nos princípios, conceitos e valores, habilidades e atitudes, reconhecidos desde a Conferência de Estocolmo, evocando a necessidade de uma consciência "esclarecida" do indivíduo em relação com a natureza e o meio ambiente para a sua preservação e conservação (UNESCO, 1972). Há então, uma chamada de atenção mundial para o ambiente humano e social, dada à crise socioambiental, geradora de complexos problemas, entre outros: a racionalidade econômica que não foi capaz de reconhecê-los como base de sustentabilidade da produção; a destruição ecológica provocada pelos processos produtivos, avanços tecnológicos e práticas de consumo, visando maximizar o benefício e excedentes econômicos em curto prazo. Como conseqüência desta lógica temos, hoje, imensas áreas desmatadas, ocasionando a erosão das terras do planeta, a diminuição dos mananciais e desaparecimento das fontes 
KNECHTEL, M. do R. Educação ambiental: origens, reformulações e avanços...

d'água, bem como a contaminação do ar, da água, dos rios, dos mares, dos solos, enfim a degradação da natureza e da qualidade de vida humana. A energia negativa do ser humano destruiu o meio ambiente.

Em face destes e outros problemas é, então, reconhecida a Educação Ambiental. Ações em nível mundial são propostas a partir da Carta de Belgrado (1975) e, assim se colocam:

Reorientação de estilos de desenvolvimento; mudança nos valores, nos comportamentos dos atores da sociedade; busca de transformação do conhecimento através de novos paradigmas, de inovação de tecnologias para resolver os problemas ambientais. Torna-se prioritária a sensibilização da sociedade para com as questões do planeta, para com o nosso habitat, por meio da educação, logicamente vinculado a disciplinas como economia, ecologia, sociologia, antropologia, política e pedagogia, portanto à relação entre as ciências do homem e da natureza.

O ser humano começa a atender com o respeito e cuidado com a vida presente na natureza, a Deusa Mãe Criadora, como os antigos povos primitivos e gregos a tratavam. O coração da natureza, a Gaya - casa planetária dos seres vivos-, começou a bater em sintonia com o coração e a razão dos homens na ciência e, por extensão na educação.

É, pois na Conferência de Tibilisi (1977, URSS) que se incorpora a dimensão ambiental na educação e se enfatiza a formação de educadores ambientais na perspectiva interdisciplinar, em todo o sistema educacional formal e não formal.

Surgem, portanto, alguns avanços, além do que, há a definição de princípios fundamentais para o desenvolvimento de grandes campos de ação para a construção de uma nova ordem social.

Continuam as reflexões, reformulações, e novas proposições na Conferência Eco-92 no Rio de Janeiro. Destacamse valiosas contribuições a começar por uma revisão e redefinição da Educação Ambiental à luz da complexidade dos problemas ambientais e dos paradigmas de ciência emergentes.
Quando a humanidade se encontra em momento de definição histórica, defrontando-se com a perpetuação das disparidades existentes entre as nações e no interior delas, com o agravamento da pobreza, da fome, das doenças, da intolerância, da violência, das guerras, com a deterioração contínua dos ecossistemas, é elaborada a Agenda XXI. ${ }^{1}$ Esta concorre para avanços significativos com um aporte substantivo para EA: dá relevância aos saberes tradicionais, reconhece no processo educacional a preocupação ética e ambientalista dos seres humanos, modificando os valores e atitudes, propiciando a construção de habilidades e mecanismos como formas sustentáveis para a atuação nos grupos e na sociedade civil; dá-se, outrossim, a valorização dos conhecimentos científicos disponíveis nas diferentes áreas para garantir as grandes transformações em todos os setores da sociedade. Incluem-se aí indústrias, universidades, governos, organizações não-governamentais e organizações comunitárias e a formação de profissionais para o gerenciamento ambiental.

A comunidade científica mundial questiona a desordem social e a imprevisibilidade do homem no universo. Há uma revolução intelectual e moral. Trata-se de moral respaldada no respeito às diferenças culturais, geográficas, religiosas, de gênero, de classes, na solidariedade, co-participação e co-responsabilidade para com a vida. É uma moral para a inclusão do outro nos processos das relações produtivas com, na e para a natureza como um todo vivo criante.

Hoje existe um mundo multicêntrico com nova representação do universo, visto como uma complexidade onde tudo se cria e se recria concomitantemente. Como diz Morin (2000), um universo que é complexo, dinâmico, genésico onde a natureza é aquilo que liga, que articula a criatividade da vida, que se manifesta em tudo e todos. É a energia criadora pulsante que se auto-organiza desde as micropartículas do átomo até a complexidade de macroseres com seus corpos dentro dos ecossistemas. O homem coloca-a como sujeito criador, integrado e ator da sociedade e da natureza. Entra-se agora, num período histórico em que os fatos, as ciências e as fronteiras estão sendo renegociados, isto é, as representações do sujeito humano é que estão sendo repensadas. (RAYNAUT, 2004). ${ }^{2}$

1 Documento histórico (700 páginas) resultante das discussões e reflexões de cientistas, pesquisadores, políticos, estudantes e professores, durante a ECO-92/RIO, em relação ao ambiente e a um desenvolvimento mais sustentável do mundo para o SEC XXI. Daí a razão do nome "Agenda XXI".

2 RAYNAUT, C. Conferência de abertura do Seminário Internacional: Interdisciplinaridade, Meio Ambiente e Desenvolvimento: Desafios e Avanços do Ensino e da Pesquisa na Pós-Graduação.Curitiba, 2004.(Dez anos de C. de Doutorado, MADE-UFPR). 
KNECHTEL, M. do R. Educação ambiental: origens, reformulações e avanços...

Em meio a estes princípios, problemas e contradições como se insere a EA no curso de Doutorado em Meio Ambiente e Desenvolvimento (MADE) da UFPR?

É integrante do conjunto de conhecimentos e da construção do programa interdisciplinar voltado ao estudo e pesquisa de um espaço social e geográfico comum, a cidadesociedade urbana e rural de Paranaguá, situada no litoral paranaense. Posteriormente, dedica-se ao estudo de outras realidades alem das fronteiras do Paraná, onde a EA se faz presente.

Como se desenvolve o processo?

Após diagnóstico inicial, a pesquisa básica compartilhada por todos, discentes e docentes, levantam-se os problemas regionais e locais. Nas oficinas de pesquisa deflagrase o processo de construção da rede de relações entre docentes, pesquisadores e doutorandos para o início da produção de conhecimento; das dinâmicas interativas identificam-se os problemas; a seguir as lógicas do Sistema Natureza: as lógicas bio-demográficas, sociais e culturais, técnicas do mercado e as lógicas de políticas públicas.

A EA, seus fundamentos e práticas perpassam as lógicas referenciadas. É, todavia, nas lógicas socioculturais que a dimensão ambiental da educação se acentua.

Da análise da situação de vida da população, das práticas sociais educativas e de saúde, bem como dos impactos ambientais, das mobilizações comunitárias e práticas ligadas ao meio ambiente, emerge a EA no ensino e na pesquisa inserida no conjunto de atividades interdisciplinares em processo.

Com base no pressuposto central da inseparabilidade entre as ciências da natureza e da sociedade surgem novas idéias, reflexões e conseqüentemente a produção de conhecimento que envolve os domínios naturais, os sociais e pedagógicos, e num diálogo constante de saberes processa-se a construção individual e coletiva do conhecimento; acredita-se na EA como uma prática interdisciplinar, entendendo-se esta como prática política, social e educativa (FOUREZ, 1995; Freire; 1980). Constrói-se e reconstrói-se o conhecimento apoiado na Metodologia da Problematização, Recensão Crítica e Seminário Interdisciplinar, buscando as conexões teóricas, os referenciais de autores atuais que trazem reformulações e avanços à epistemologia da educação socioambiental como: de Maguerez (BORDENAVE; PEREIRA,1982); Berbel (1994-1996); Knechtel (1999-2003), Capra (2002), Morin (2000-2001), Leff (2001), Raynaut (1996), Floriani (2000-2003), Gonzales Gaudiano (1997), Sauvé (1999-2000), Medina (1994), e outros.
Num olhar para a finalização do século XX e inícios do século XXI, o mundo oscila entre a modernidade e a pós-modernidade, ora gerando perplexidades, ora incertezas. Reformulações nos princípios, descobertas e avanços impulsionam o "aprender a aprender", a reconstrução e construção de conhecimentos, sem perder de vista a relação eco-socio-política sustentável, incluindo a educação.

Sem dúvida a EA é um componente nodal e não um simples acessório da educação; envolve a reconstrução do sistema de relações entre pessoas, sociedade e conhecimento; vale-se da pesquisa e do diálogo com os mais diversos saberes, científicos e não científicos, pedagógicos e não pedagógicos "em espaços de fronteiras onde se encontram razão e emoção, pensamento e vida, culturas e identidades" (SAUVÉ, 1999; FOUREZ, 1995; FREIRE, 1980).

Duas tendências culturais dominantes coexistem no mundo: a modernidade e a pós-modernidade.

A modernidade, como movimento globalizante originário dos países ocidentais, representa uma mudança nas instituições conforme a organização social e os estilos de vida europeus que emergiram a partir do século XVII. Segundo Giddens (1991, p. 65), a modernidade gira em torno de quatro dimensões institucionais básicas: “a) o industrialismo; b) o capitalismo; c) a vigilância no que se refere à supervisão das atividades da população e o controle da informação; d) e o poder militar".

A globalização do industrialismo e do progresso tecnológico reorganiza a produção, altera as relações sociais e as relações com o meio ambiente.

Algumas características da modernidade podem ser assim, sinalizadas: há uma crença no progresso associado à explosão do conhecimento científico às promessas científicas. A epistemologia moderna apóia-se na racionalidade, na objetividade, ela é mecanicista, positivista, linear, portanto, dá ênfase à racionalidade instrumental para legitimar o conhecimento produzido.

Na modernidade, o marco epistemológico tem como proposta a busca do sentido, busca da consistência, de relevância do conhecimento e de reflexão epistemológica, ética, estética e socioeducativas, mas deixa de dialogar com as múltiplas dimensões do problema e das lógicas distintas do natural e do social, do físico e do humano.

Enquanto que a pós-modernidade caracteriza-se pela ruptura de ordens anteriores, gera questionamentos que impulsionam a construção de novos paradigmas do conhecimento, descobrindo os limites das explicações metodológicas do pensar racionalista, cartesiano e newtoniano. 
KNECHTEL, M. do R. Educação ambiental: origens, reformulações e avanços...

A epistemologia da educação socioambiental pósmoderna propõe: a construção do conhecimento da educação socialmente crítica baseada em novas racionalidades de saberes, em um processo de análise das realidades ambientais, sociais e educacionais inter-relacionadas com a finalidade de transformá-las.

Na pós-modernidade busca-se a integração dos saberes, não como modelo, todavia como pesquisa aberta ao diálogo de saberes; apresenta argumentos que orientam o repensar, o reorganizar a pesquisa diante das conseqüências evidenciadas pelo sistema de conhecimentos que norteiam as relações homem-natureza.

A educação socioambiental no processo interdisciplinar em construção preconiza uma produção dinamicamente associada aos movimentos sociais, multiculturais, aos impactos ambientais, sociais e culturais, às mudanças comunitárias no contexto de vida das populações, às práticas sociais educativas que permitam a inclusão. São estes os sinalizadores de pesquisa, de objetos de estudo de uma educação socioambiental permanente.

Outrossim, docentes pesquisadores do curso de doutorado, compreendendo as necessidades e a falta de profissionais em EA para enfrentar os desafios constantes dos problemas ambientais locais e regionais, incluíram a proposta de formação do educador ambiental com o objetivo de "qualificar profissionais de diversas áreas de conhecimento na realidade socioambiental e tendo como referência a relação homem-natureza" (Regimento do Curso, 1998), a pedagogia do movimento complexo, um fazer pedagógico coerente com a concepção de educação socioambiental defendida pela percepção crítica da realidade. Completase com a busca de uma pedagogia da autonomia (FREIRE) que pela participação solidária e cooperativa transforma a realidade, em suas múltiplas determinações, para a construção de uma nova sociedade ambientalmente sustentável.

Nesse sentido, atendendo sugestão de autoridades dos órgãos da educação e do meio ambiente, na I Conferência Nacional de Educação Ambiental em Brasília (1998), em 2002 é proposto o curso de pós-graduação, em nível de Especialização: Educação, Meio Ambiente e Desenvolvimento, no contexto do Curso de Doutorado. Conta com a participação dos docentes e pesquisadores da UFPR, além de alguns convidados externos. Agora, já em sua $4^{\text {a }}$ Turma, com significativa demanda, os estudos monográficos apresentam princípios e valores, que evidenciam as relações homem-natureza na construção dos referenciais teóri- cos apoiados na epistemologia da educação ambiental, apontando transformações e avanços à educação socioambiental formal e não formal.

Há ainda que se fazer referência à lei 9795 de 27/04/ 1999 que institucionaliza e dispõe sobre a Política Nacional de EA e dá outras providências.

Apresenta o conceito de EA e responsabiliza as instituições quanto ao processo educativo mais amplo, isto é, que todos têm direito a EA, incumbindo também empresas, entidades de classe, instituições públicas e privadas a promover programas destinados à capacitação dos trabalhadores, inclusive dos professores, em nível nacional, regional e local.

Em síntese, na busca de soluções práticas, em termos de avanços uma dupla mudança se desenha, conforme o Prof. Raynaut (2004), que diz:

é evidente a extraterritorialidade segundo a qual todos compartilham a mesma genealogia; o ser humano se destaca pela consciência e pelo pensar em si mesmo. Criar sentidos e perspectivas são características próprias do ser humano, as idéias por si mesmo geram novas idéias. Muitas guerras e sangue foram derramados, todavia muitas descobertas e inovações foram criadas.

Esses sinais de movimento e de transição revelam alguns avanços no ensino e na pesquisa da pós-graduação; revelam o caráter dinâmico da construção de conhecimentos, do conjunto de idéias, de valores e de práticas que permeiam os estudos de Educação Ambiental como uma das possibilidades à melhoria de qualidade de vida dos povos.

Das reflexões expostas pode-se inferir que:

- a ciência, frente aos novos avanços, tem um papel fundamental: o de permitir novas tendências, isto é, de ir além das simplificações, de tratar da complexidade do mundo e das complexidades ambientais interdisciplinarmente;

- é fundamental que o ambiente como objeto de estudo, não seja tratado isolado de outros fatores, mas como uma dimensão que impulsiona e sustenta as atividades e os aspectos biológicos, físico-ecológicos, econômicos, socioculturais dos seres humanos;

- é na busca da totalidade como categoria de análise que a problemática ambiental se constitui no conteúdo histórico-social e cultural da EA; 
KNECHTEL, M. do R. Educação ambiental: origens, reformulações e avanços...

- o problema central da Educação Ambiental, portanto, está conectado à questão epistemológica fundamental da natureza do conhecimento - como os estudantes conhecem os conteúdos socioambientais, e também como pesquisam e aprendem.
É nesse exercício, difícil, que o maior desafio se coloca: $\mathrm{o}$ ser humano frente às suas necessidades básicas busca satisfação, cria, recria, transforma-se a si mesmo; constróise e reconstrói-se, num processo contínuo no espaço e no tempo histórico.

\section{REFERÊNCIAS}

BERBEL, N. A. N. Metodologia da problematização: uma alternativa metodológica apropriada para o ensino superior. Revista Semina. Londrina, 1994. Edição especial. 1994.

. Metodologia do ensino superior. São Paulo: Papirus,

BORDENAVE, J. D.; PEREIRA, A. M. Estratégias de ensino aprendizagem. 4. ed. Petrópolis: Vozes, 1982.

CAPRA, F. As conexões ocultas - ciência para uma vida sustentável. São Paulo: Cultrix, 2002.

CARNEIRO, S. C. A dimensão ambiental da educação escolar na rede escolar pública de Paranaguá. Curitiba, 1999. Tese (Doutorado) - Universidade Federal do Paraná.

CASTELLS, M. A Sociedade em rede. São Paulo: Paz e Terra, 1999, v. 1.

CORDEIRO, M. E. F; FLORIANI, D. Políticas de educación ambiental y formación de capacidades para el desarrollo sustentable. In: LEFF, E. et al. (Org.). La trasición hacia el dessarrollo sustentable. Perspectivas de América Latina y el Caribe. México: PNUMA, INE, UAM, SEMARN, 2002. p. 141-159.

DEMO, P. E. Educação e conhecimento: relação necessária, insuficiente e controversa, Petrópolis: Vozes, 2000.

DE SOUZA SANTOS, B. Introdução a uma ciência pós-moderna. Rio de Janeiro: Graal, 1989.

DITTRICH, M. G. Natureza e criatividade. Itajaí: Univalli, 2002.

FAZENDA, I. Integração interdisciplinar no ensino brasileiro. São Paulo: Loyola, 1979.

Interdisciplinaridade: história, teoria e pesquisa. São Paulo: Papirus, 1994.

Interdisciplinaridade: um projeto em parceria. São Paulo: Loyola, 1991.
FLORIANI, D. Interdisciplinaridade: teoria e prática de pesquisa e do ensino no doutorado em meio ambiente e desenvolvimento (UFPR). Curitiba: UFPR, 1997/99.

Doutorado em meio ambiente e desenvolvimento: avaliação e expectativas para a interdisciplinaridade. Cadernos de desenvolvimento e meio Ambiente, n. 3, Curitiba: UFPR, 1996.

. Marcos conceituais para o desenvolvimento da interdisciplinaridade. Interdisciplinaridade em ciências ambientais. São Paulo: Signus, MCT, 2000, p.85-108.

. Diálogos interdisciplinares para uma agenda socioambiental: breve inventário do debate sobre ciência, sociedade e natureza. Desenvolvimento e meio ambiente. Curitiba: UFPR, n. 1, jan./jun. 2000.

. A complexidade ambiental nos convida a dialogar com as incertezas da modernidade. Desenvolvimento e meio ambiente. Curitiba: UFPR, n. 4, jul./dez. 2001.

. Conhecimento, meio ambiente e globalização. Curitiba: Juruá - PNUMA, 2003. 173 p. Série Pensamento Ambiental Latino-Americano.

.; KNECHTEL, M. R. Educação ambiental: epistemologia e metodologias. Curitiba: Vicentina, 2003.

FOUREZ, G. A construção das ciências. São Paulo: Unesp, 1995.

FREIRE, P. Conscientização: teoria e prática da libertação. Uma introdução ao pensamento de Paulo Freire. 3. ed. São Paulo: Moraes, 1980.

Pedagogia da autonomia. Saberes necessários à prática. 23. ed. São Paulo: Paz e Terra, 2002.

GIDDENS, A. A constituição da sociedade. São Paulo: Martins Fontes, 1989.

GONZÁLEZ GAUDIANO, E. Educación ambiental. México: Sistemas Técnicos de Edición, 1997. 
KNECHTEL, M. do R. Educação ambiental: origens, reformulações e avanços...

HELLEWR, A.; FEHÉR, F. A condição politica pós-moderna. Rio de Janeiro: Civilização Brasileira, 1998.

HOBSBAWN, E. Era dos extremos: o breve século XX (19141991). São Paulo: Companhia das Letras, 1995.

HORGAN, J. O fim da ciência. Uma discussão sobre os limites do conhecimento científico. São Paulo: Companhia das Letras, 1998.

HOSLE, V. Philosophie der Ökologischen Krise. Moscou: Moskaner Vorträge. Beck, Scher Rehie, 1990.

LEFF, E. Sociologia y ambiente: sobre el concepto de racionalidad ambiental y as transformaciones del conocimiento. In: VIEIRA, P. F.; MAIMON, D. (Org.). As ciências sociais e a questão ambiental: rumo à interdisciplinaridade. Rio de Janeiro: APED (Associação de Pesquisa e Ensino em Ecologia e Desenvolvimento); Belém: Universidade Federal do Pará, 1993. p. $95-130$.

. Saber ambiental, sustentabilidade, racionalidade, complexidade, poder. Petrópolis: Vozes, 2001.

LÉVY, P. As tecnologias da inteligência: o futuro do pensamento na era da informação. São Paulo: Editora 34, 2000.

LUDKE, M.; ANDRÉ, M. E. D. A pesquisa em educação: abordagens qualitativas. São Paulo: Pedagógicas e Universitária, 1986.

LUZ, G. F. Formação de formadores em educação ambiental nos cenários da região metropolitana de Curitiba. Curitiba, 2001. Tese (Doutorado em Meio Ambiente e Desenvolvimento) - Universidade Federal do Paraná.

MACHADO, N. J. Epistemologia e didática. São Paulo: Cortez, 1995.

MATURAMA, H. A biologia do conhecer: suas origens e implicações. A ontologia da realidade. Belo Horizonte: UFMG, 2001. p. 31-52.

MEDINA, N. M. Elementos para introdução da dimensão ambiental na educação escolar. Brasília: UFMT, 1994.

MENDONÇA, F. et al. Gestão ambiental e condições de vida na cidade. Curitiba: MAD - UFPR, 1996.
MORIN, E. Ciencia con Conciencia. Barcelona: Anthropos, 1984.

Os sete saberes necessários à educação do futuro. São Paulo: Cortez, 2000. 1995.

; KERN, A. B. Terra - Pátria. Porto Alegre: Sulina,

PIAGET, J. L'Épistémologie et ses variétés. Logique et connaissance scientifique. Encyclopédie de la Pléiade, Paris: Gallimard, 1967. p. 3-62. 2002.

Epistemología genética. São Paulo: Martins Fontes, 1975

Estudos sociológicos. Rio de Janeiro: Nova Fronteira,

PRIGOGINE, I. O fim das certezas. Tempo, caos e as leis naturais. São Paulo: Unesp, 1996.

RAYNAUT, C. Processo de construção de um programa interdisciplinar de pesquisa no quadro do doutorado em meio ambiente e desenvolvimento. Cadernos de desenvolvimento e meio ambiente. Curitiba: UFPR, 1996.

SAUVÉ, L. La educación ambiental entre la modernidad y la pos-modernidad: in busca de um marco de referencia educativo integrador. Tópicos en educación ambiental, México, v. 1, p. 7-11, 1999.

Sete experimentos que podem mudar o mundo. Pode a ciência explicar o inexplicável? São Paulo: Cultrix 1999.

TOURAINE, A. Crítica da modernidade. Petrópolis: Vozes, 1993.

UNESCO. Conferência Mundial. Art. 5, letra a.

VASQUEZ, A. S. Filosofia da práxis. 4. ed. Rio de Janeiro: Paz e Terra, 1977.

VYGOTSKI, L. A formação social da mente. São Paulo: Martins Fontes, 1998.

WEIL, P. et al. Rumo à nova transdisciplinaridade. São Paulo: Summus, 1993. 